\title{
Analysis and Solution of the Problems in Professional Postgraduate Practice Bases
}

\author{
Zheng Zheng, Yongshuai Wang, Jianxing Jin, kaili \\ Guo \\ School of electrical engineering and automation \\ Henan polytechnic university \\ Jiaozuo City, China \\ zhengzh@hpu.edu.cn
}

\author{
Jun Zhu* \\ School of electrical engineering and automation \\ Henan polytechnic university \\ Jiaozuo City, China \\ zhujun@hpu.edu.cn
}

\begin{abstract}
According to the state's aim of accelerating the training of high-quality and applied professional degree postgraduates, Henan Polytechnic University and Xu Ji Electric jointly built the Henan Province Graduate Education Innovation Base, the base played an important role in the implementation of the professional practice of professional degree graduate students in our school. The paper analyzes the contradiction of insufficient practice time in professional practice from different angles, and proposes reasonable solutions from different aspects of students, schools and enterprises. At the same time, the specific cases of students practicing at the base are explained.
\end{abstract}

Keywords-Professional degree graduate; Professional practice; Existing problems; Solution

\section{INTRODUCTION}

In order to meet the needs of economic and social construction and development, accelerate the training of professional applied talents, in 2009 China began to recruit full-time professional degree graduate student who are mainly fresh graduates[1-3]. The goal of full-time professional postgraduate training is to cultivate professional ability to solve practical problems, to be able to independently undertake the engineering project's ability and related technical management work, and to have high-level engineering talents with good professionalism[4-6]. The main difference between professional postgraduates and academic postgraduates is the cultivation mode centered on the promotion of practical ability.

Under the background of advocating the cultivation of high-level application-oriented professionals, in order to strengthen the practical skills of graduate students, the practice base of graduate school-enterprise joint training has sprung up. On February 8, 2018, Henan Polytechnic University and Xu Ji Electric Group jointly established the "Henan Province Graduate Education Innovation Training Base" officially opened. The construction of the base takes the upgrading of professional skills of graduate students as the core and the sharing of resources, mutual benefit and common development as the principle. It actively explores the new mode of cultivating graduate students' innovative ability, gives full play to the advantages of both sides in academic teams, technical projects, research platforms and experimental equipment, promotes the reform and innovation of the cultivation

Found Program: Higher Education Teaching Reform Research and Practice in Henan province (2017SJGLX033Y), Professional Degree Graduate Education Comprehensive Reform in Henan Polytechnic University (2016YZG03), Postgraduate Case Database Course Construction (2017YAL03,2016YA L11) mechanism of graduate students, and enhance the independent innovation ability, practical ability and comprehensive quality of postgraduates.

\section{PROBLEMS IN THE PROCESS OF PRACTICE}

The establishment of a postgraduate education innovation training base provides a full-time professional postgraduate with a way to acquire professional skills as a student, and enhance the employment competitiveness of professional postgraduates. In the professional master's training program, students need not only school tutors, but also enterprise tutors. At the same time, students need to complete the teaching plan under the joint guidance of school tutors and enterprise tutors. Relying on the postgraduate education innovation training base, the school can select practical and experienced engineers as the professional tutors of professional postgraduates. The professional postgraduate students can personally participate in on-site production practice, enrich their professional practice experience and enhance their professional skills.

For professional postgraduates, different from on-the-job postgraduates, the professional postgraduate students enrolled in the school are generally fresh graduates. So professional postgraduates generally lack social experience and practical ability to exercise. At the same time, many employers need certain work experience in recruiting. Therefore, professional graduate students have a strong desire to participate in professional practice.

For schools, besides completing compulsory courses and elective courses, students also need to publish papers at a specified level. The writing of papers needs to consult a large number of documents, at the same time, theoretical calculations and simulation models need to be built. If necessary, experiments should be done to verify the correctness of the conclusions. Therefore, students need to spend a lot of time on completing papers. The length of professional postgraduates schooling is generally three years, and the first year requires the completion of basic compulsory and elective courses. Academic papers and graduation thesis are required in the second and third years. Therefore, under the above circumstances, students can only take a certain amount of time to carry out professional practice. Professional practice within the prescribed time has limitations for the improvement of practical experience and technical level. 
On the one hand, professional postgraduates are eager to have a long time to participate in professional practice in order to gain rich practical experience and professional practical skills; on the other hand, due to some other factors such as the graduation requirements of the school, professional practice time cannot effective guarantee. With the in-depth reform of professional postgraduate training program, this contradiction (hereinafter referred to as the contradiction of insufficient practice time) gradually emerged.

\section{SOLUTIONS TO PROBLEMS IN PRACTICE}

There are many reasons for the lack of professional practice time. First of all, students are unreasonable about the schedule of learning progress. Second, with the continuous development and progress of the society, the employer's requirements for students are getting higher and higher. In order to meet the requirements of employers, students tend to be able to carry out on-site professional practice to enhance professional skills after completing the school's required graduation requirements, while students also need to meet the school's graduation requirements.

Professional postgraduates themselves should not be relaxed about their own requirements. They should lay a solid foundation in the first year of graduate study. After studying the optional courses and compulsory courses, we should read the literature extensively, and make sufficient preparations for writing papers later. At the same time, we must actively master the use of various equipment and tools in the laboratory, and have a thorough understanding of the models and performance of the commonly used devices in the laboratory, laying the foundation for future experiments. Fast-moving students can complete their academic papers by the second year of graduate students, thus allowing more time for professional practice.

The school plays a very important role in the implementation of postgraduate practice education. The school's instructional programs for students generally include professional practice, but in order to cope with other projects in the teaching plan, such as the study of basic courses, the study of professional courses, and the writing of papers, professional practice time is often arranged less. Therefore, in the training plan, in addition to the theoretical knowledge course, the time of professional practice should be increased as much as possible so that students can fully improve their professional skills on the spot.

\section{PROFESSIONAL PRACTICE TYPICAL CASE}

Henan Polytechnic University and $\mathrm{Xu}$ Ji Electric jointly built the Henan Province Graduate Education Innovation Base, and $\mathrm{Xu} \mathrm{Ji}$ Electric Group has more than 20 electrical subsidiaries. Our students can be assigned to their respective subsidiaries for professional practice based on their professional and research direction.

$\mathrm{Xu} \mathrm{Ji}$ intelligent power supply company. Students can access a wide variety of monitoring and control cabinets, protective cabinets, switch cabinets, comprehensive protection equipment and other relay protection equipment. Students can use the equipment flexibly through hands-on operation, after having an overall understanding of it, under the guidance of enterprise tutors, understand the working principle and wiring diagram of each device, learn to apply book knowledge to practice, understand the truth that the so-called "what's learned from books is superficial after all, it's crucial to have it personally tested somehow." There is a certain gap between any theory and the final practice, which must be repeated to find problems and solve problems of multiple cycles, which is a professional degree graduate students through professional practice to possess a quality.

The testing department of the national electric power electronics research center of $\mathrm{Xu} \mathrm{Ji}$. Students can practice and study all kinds of testing items before the equipment leaves the factory, although it is a bit cumbersome, it is of great benefit to improve the professional quality of professional degree graduates, consolidate their professional knowledge and familiarize themselves with the company's workflow. The busy and fulfilling professional practice every day is not only a test for students, but also a rare opportunity to work hard and sublimate yourself.

$\mathrm{Xu} \mathrm{Ji}$ Power Company. It is a professional enterprise engaged in the research and development of power electronic products, system design and production. Students in this department understand the charging and replacing system of electric vehicles, power supply, power quality control equipment, military special power supply and other high-tech fields. The department's company exchanges and collaborates with well-known institutes in the power electronics industry such as Tsinghua University, Huazhong University of Science and Technology, and Zhejiang University. Students practice professionally in this department, and they can participate in various production links and improve their hands-on practical skills and social experience. Xu Ji power company's products are in the leading position, so that students are more familiar with the industry development trends, and provide a good help for future employment. At the same time, the company has frequent exchanges with domestic first-class electric universities, and students learn about academic research in first-class universities in the course of practice. Therefore, professional practice is a key link in postgraduate education. It is necessary to grasp this link. Only in this way can we export high-quality, comprehensive and applied talents for the society.

\section{CONCLUSION}

Henan Polytechnic University and $\mathrm{Xu} \mathrm{Ji}$ Electric jointly built the Henan Province Graduate Education Innovation Base, and $\mathrm{Xu} \mathrm{Ji}$ Electric Group has more than 20 electrical subsidiaries. Our students can be assigned to their respective subsidiaries for professional practice based on their professional and research direction.

The introduction of the full-time professional degree postgraduate training policy conforms to the needs of the national economic development for high-level applied talents, and establishes a postgraduate innovation practice base in order to meet the training objectives. Schools and enterprises participate in the training of professional postgraduate students in the postgraduate professional practice. 
Students should plan their graduate study career in detail, be solid in their professional knowledge, and learn to use the various equipment and tools of the experiment to prepare for the completion of the school's projects and participation in offcampus practice.

The school should develop a training plan for professional postgraduates and adapt to the corporate society, change the graduation requirements for professional degree graduates, reduce unnecessary public courses, and increase the practice time of professional degree graduate students.

Enterprises should actively play the role of corporate tutors in the development process of postgraduate training programs, and give full play to the role of corporate tutors in the postgraduate practice.

Give full play to the respective advantages of school tutors and corporate tutors to achieve an organic integration of research and practice. Create a good environment conducive to the development of professional postgraduate education.

\section{ACKNOWLEDGMENT}

This research was financially supported by the Higher Education Teaching Reform Research and Practice in Henan province (2017SJGLX033Y), Professional Degree Graduate Education Comprehensive Reform in Henan Polytechnic
University (2016YZG03), Postgraduate Case Base Course Construction (2017YAL03, 2016YAL11) and Henan Polytechnic University - Xu Ji Electric jointly built the Henan Province Graduate Education Innovation Base.

\section{REFERENCES}

[1] Lin Guijuan, Yu Chaomei, Wang Tian, "Research on the Construction Model of Professional Degree Postgraduate Practice Base,” Chinese Agricultural Education, vol. 1, pp. 50-52+96, 2012.

[2] Chen Jing, "Research on the Development of Professional Degree Graduate Education Development Issues in China," Southwest University, 2013.

[3] Gao Hong, "Reforming the Professional Degree Graduate Training Mode and Perfecting the High-level Applied Talents Training System," [Chinese Vocational and Technical Education, vol. 21, pp. 94-97, 2014.

[4] Liu Tianyu, "Research on the Practical Teaching System of Electrical Engineering Masters-Take the professional postgraduate training of electrical engineering in Shanghai Dian Ji University as an example,” Education Teaching Forum,vol. 36, pp. 196-197, 2016

[5] Liang Zhenshu, Song Guiyun, Li Changmo, "Discussion on Promoting Emp loy ment Competitiveness by Constructing the Practice Base of Fulltime Engineering Masters," China Electric Power Education, vol. 22, pp. 199-200+207, 2013

[6] Ma Shihong, "Research on Assessment of Competency Structure For Full-time Masters of Engineering,” University of Science \& Technology Beijing, 2015. 